\title{
FRACIONAMENTO A SECO DA FARINHA DE AVEIA E MODIFICAÇÃO QUÚMICA DA FRAÇÃO RICA EM AMIDO' ${ }^{1}$
}

\author{
Ana Paula DANIEL ${ }^{2,3}$, Vivian Caetano BOCHI ${ }^{2}$, Camila STEFFENS ${ }^{4}$, \\ Leila Picolli da SILVA ${ }^{5}$, Tatiana EMANUELLI ${ }^{4, *}$
}

\begin{abstract}
RESUMO
O estudo teve por objetivo obter frações de farinha de aveia enriquecidas em amido e em fibras pelo fracionamento a seco e modificar quimicamente (fosfatação) o amido da fração rica neste constituinte, avaliando suas propriedades funcionais. O fracionamento foi efetuado utilizando-se as granulometrias > 300, 212-300, 150-212, e <150 $\mu \mathrm{m}$. As frações $>300 \mu \mathrm{m}$ e $212-300 \mu \mathrm{m}$ foram semelhantes, com aumento de aproximadamente 1,5 e 2,7 vezes nos teores de proteína e fibra, e redução de 0,5-0,6 vezes no teor de amido, quando comparadas à farinha integral. As frações $212-150 \mu \mathrm{m}$ e $<150 \mu \mathrm{m}$ foram semelhantes entre si e apresentaram os maiores teores de amido (aproximadamente $70 \%$ ). A fração rica em amido $<150 \mu \mathrm{m}$, que apresentou maior rendimento no fracionamento $(35,5 \%)$, foi fosfatada usando tripolifosfato de sódio a $150-155{ }^{\circ} \mathrm{C}$, por 20 e $40 \mathrm{~min}$, resultando em 0,39 e $0,32 \%$ de fósforo ligado, respectivamente. Nas frações de amido fosfatadas a capacidade de ligação de água fria aumentou (1,9-3,3 vezes), enquanto a sinérese a $5{ }^{\circ} \mathrm{C}$ ou após congelamento/descongelamento foi reduzida (6-20 e 5-6 vezes, respectivamente) significativamente quando comparadas à nativa. A fosfatação reduziu o aumento de opacidade dos géis de amido durante armazenagem a $5{ }^{\circ} \mathrm{C}$, indicando menor tendência a retrogradação. Assim, o fracionamento a seco da farinha de aveia proporcionou frações ricas em proteínas e fibras ou ricas em amido, e a fosfatação da fração enriquecida em amido melhorou suas propriedades funcionais, o que pode ampliar o potencial de aplicação e o valor econômico dessa fração na indústria de alimentos.
\end{abstract}

Palavras-chave: amido de aveia, peneiramento, amido monoéster fosfato, sinérese, capacidade de ligação à água a frio

\section{SUMMARY}

DRY FRACTIONATION OF OATMEAL AND CHEMICAL MODIFICATION OF STARCH RICH FRACTION. The objective of this study was to obtain starch and fiber enriched oatmeal fractions through sieving, chemically modifying (phosphorylation) the starch enriched fraction, and evaluating its functional properties. Fractionation was performed using $>300,212-300,150-212$, and $<150 \mu \mathrm{m}$ sieve. Fractions $>300 \mu \mathrm{m}$ and $212-300 \mu \mathrm{m}$ were similar and had increased protein and fiber content ( 1.5 and 2.7 fold), but reduced starch content (0.5-0.6 fold) when compared to whole oatmeal. Fractions $212-150 \mu \mathrm{m}$ and $<150 \mu \mathrm{m}$ were similar and had the highest starch content (around 70\%). The starch-rich fraction $<150 \mu \mathrm{m}$ that had the highest yield during sieving (35.5\%) was phosphorylated with sodium tripolyphosphate at $150-155{ }^{\circ} \mathrm{C}$ for 20 and $40 \mathrm{~min}$, yielding 0.39 and $0.32 \%$ phosphorus bound, respectively. Cold water binding capacity increased (1.9-3.3 fold), while syneresis at $5{ }^{\circ} \mathrm{C}$ or after freezing/thawing was significantly reduced (6-20 and 5-6 fold, respectively) in phosphorylated starch fraction when compared to the native starch fraction. Phosphorylation reduced the increase of pasta opacity during storage at $5{ }^{\circ} \mathrm{C}$, which indicates a lower retrogradation tendency. Thus, oatmeal sieving yielded fractions either enriched in fiber and protein or enriched in starch. Moreover, phosphorylation of the starch-rich fraction improved their functional properties, which may increase the potential applicability and economic value of this fraction in the food industry.

Keywords: oat starch, sieving, starch phosphate monoester, syneresis, cold water binding capacity.

\section{1 - INTRODUÇÃO}

A aveia apresenta excelente qualidade nutricional, o que está intimamente relacionado com os seus elevados teores em $\beta$-glucanas e sua qualidade protéica, que são superiores

\footnotetext{
${ }^{1}$ Recebido para publicação em 3/5/2006. Aceito para publicação em 20/10/2006 (001740)

${ }^{2}$ Programa de Pós-Graduação em Ciência e Tecnologia dos Alimentos, Centro de Ciências Rurais (CCR),

Universidade Federal de Santa Maria (UFSM)

${ }^{3}$ Departamento de Fisiologia e Farmacologia,

Centro de Ciências da Saúde (CCS),

Universidade Federal de Santa Maria (UFSM)

${ }^{4}$ Departamento de Tecnologia e Ciência dos Alimentos,

Centro de Ciências Rurais (CCR),

Universidade Federal de Santa Maria (UFSM), CEP 97105-900,

Santa Maria (RS), Brasil,

E-mail: tatiemanuelli@smailr.ufsm.br

${ }^{5}$ Departamento de Zootecnia, Centro de Ciências Rurais (CCR),

Universidade Federal de Santa Maria (UFSM), CEP 97105-900,

Santa Maria (RS), Brasil

* A quem a correspondência deve ser enviada
}

aos demais cereais [21,27]. No sentido de aumentar sua utilização e seu valor econômico, alguns estudos têm proposto o uso da aveia como matéria-prima para a preparação de concentrados destes nutrientes [2, 19, 21, 27, 39]. A obtenção de frações com concentrações diferenciadas de proteínas e de $\beta$-glucanas poderia facilitar estudos clínicos e de avaliação das propriedades desses componentes em alimentos [2].

As frações ricas em fibra, compostas predominantemente de $\beta$-glucanas, por exemplo, podem ser indicadas para uso como ingredientes nutracêuticos, substitutos da gordura em sorvetes, espessantes de molhos e na formulação de almôndegas e embutidos cárneos [5, 27, 40]. Já as frações ricas em proteínas, com elevado valor nutritivo, fruto de um bom balanceamento de aminoácidos [30], podem ser indicadas para a produção de pães, alimentos infantis, dietas para esportistas e alimentos geriátricos [27].

Uma forma de se obter frações ricas nos diferentes nutrientes é pelo fracionamento a seco da farinha de aveia. 
Estudo realizado por SÁ [27] demonstrou que, quantitativamente, a principal fração obtida por este procedimento é aquela rica em amido, a qual apresenta baixo valor comercial e tem limitada aplicação industrial, tornando o processo pouco atrativo sob o ponto de vista econômico.

O amido da aveia possui propriedades físico-químicas consideravelmente diferentes dos amidos de outras fontes, sendo os seus grânulos compostos e poliédricos, com tamanho variando entre 3 a $10 \mu \mathrm{m}$ e apresentando temperatura de gelificação em torno de $55{ }^{\circ} \mathrm{C}$ [12, 15, 35, 42]. Porém, a obtenção do amido de aveia é difícil, pois existe uma intensa associação dele com proteínas, lipídios e fibras. Sendo assim, as temperaturas de gelificação de frações de farinha de aveia enriquecidas em amido geralmente são superiores as do amido de aveia isolado [42].

Assim como os amidos de outras fontes, o amido de aveia nativo exibe propriedades reológicas (insolubilidade em água fria, instabilidade frente a ciclos de congelamento e descongelamento e tendência a retrogradação) que limitam a sua aplicação industrial. Além disso, as fibras (especialmente as B-glucanas) exercem grande influência no aumento da viscosidade da farinha de aveia [6, 7]. Por conseqüência, a modificação das propriedades reológicas do amido de aveia nativo por processos físicos (pré-gelatinização) ou químicos (oxidação, fosfatação, acetilação) pode ampliar seu espectro de uso na indústria de alimentos.

A modificação química do amido por fosfatação caracteriza-se por aumentar o poder de inchamento e a solubilização dos grânulos, além de reduzir a temperatura de gelificação, bem como aumentar a claridade da pasta e a viscosidade do gel [28, 32, 33]. Além disso, as pastas de amido fosfatado possuem maior estabilidade durante a armazenagem e frente aos ciclos de congelamento/descongelamento, possibilitando seu uso em produtos congelados ou enlatados [4, 17, 20, 36].

Dentro deste contexto, o presente trabalho teve por objetivo obter frações de farinha de aveia ricas em fibras e frações ricas em amido pelo fracionamento a seco, bem como modificar quimicamente a fração rica em amido por fosfatação e, por fim, avaliar as propriedades funcionais da fração amilácea modificada.

\section{2 - MATERIAL E MÉTODOS}

\section{1 - Material}

A farinha de aveia (Avena sativa, L.) utilizada no experimento foi obtida pela mistura de grãos das cultivares UFRGS 14 e 19 (2002), oriundas da Estação Experimental da Universidade Federal do Rio Grande do Sul (Eldorado do Sul - RS).

Nas determinações de fibra alimentar e amido, foram utilizadas as enzimas: $\alpha$-amilase (Termamyl $120 \mathrm{~L}^{\circledR}$ ), protease (Flavourzyme ${ }^{\circledR}$ ) e amiloglicosidase (AMG 300L ${ }^{\circledR}$ ), fornecidas pela Novozymes Latino America Ltda (Araucária, PR, Brasil). A glicose liberada durante a hidrólise do amido foi deter- minada usando um kit glicose-oxidase-peroxidase (Glucox 500), fornecido pela Doles (Goiânia, GO, Brasil).

\section{2 - Métodos}

\subsection{1 - Obtenção da farinha}

Os grãos foram previamente descascados em moinho de rolo e pulverizados por moagem em moinho tipo Willey, sendo o tamanho da peneira na saída do moinho de $1 \mathrm{~mm}$. Para o desengorduramento da farinha, utilizou-se n-hexano na proporção de 1:4 (m/v), por $24 \mathrm{~h}$. A seguir, as amostras foram secas em estufa com ventilação de ar forçado a $45{ }^{\circ} \mathrm{C}$, por $3 \mathrm{~h}$, e novamente pulverizadas em micromoinho analítico de mesa (IKA, modelo A10).

\subsection{2 - Fracionamento}

No momento do fracionamento, a farinha de aveia desengordurada foi novamente seca em estufa de ar forçado a $45^{\circ} \mathrm{C}$ por $3 \mathrm{~h}$, evitando com isso a formação de aglomerados pela presença de umidade. Para a concentração dos nutrientes da farinha desengordurada por diferenças granulométricas, utilizou-se um conjunto de peneiras de aço inoxidável com aberturas de 300, 212 e $150 \mu \mathrm{m}$, em aparelho batedor rotatório com reostato na potência 9 , por um tempo total de $1 \mathrm{~h}$, tendo intervalos de 5/5 min para homogeneização da amostra. Para cada fracionamento, foi utilizado em média $100 \mathrm{~g}$ de amostra previamente pesada, resultando nas frações: > $300 \mu \mathrm{m}$, intermediárias (> $212-<300 \mu \mathrm{m}$ e > 150 $<212 \mu \mathrm{m}$ ) e $<150 \mu \mathrm{m}$. Após a obtenção, as frações foram embaladas, identificadas e mantidas a $-20^{\circ} \mathrm{C}$ até o momento das análises. O rendimento do processo foi calculado por diferença de peso e expresso em percentual.

\subsection{3 - Composição química e coloração das frações}

Os teores de cinzas (método 923.03), umidade (método 925.10), extrato etéreo (método 920.39, com hidrólise ácida) e proteína bruta (método 960.52, fator de conversão: 5,83 ) foram analisados conforme as metodologias descritas pela AOAC [1]. As fibras alimentares total e insolúvel foram determinadas pelos métodos 985.29 e 991.42 da AOAC [1], sendo a fibra solúvel calculada por diferença. Os amidos digerível e resistente foram determinados de acordo com o método 996.11 da AOAC [1], revisado em 1998, e seguindo as modificações propostas por WALTER [37], que recomenda a utilização de maior quantidade de amostra (300 mg ao invés de $100 \mathrm{mg}$ ), tampão fosfato pH 6,8 ao invés de MOPS (ácido 4-morfolino propano sulfônico), pH 7,0, e proteólise durante o processo de digestão.

Para determinar a coloração das frações, utilizou-se o colorímetro Minolta Chroma Meter CR-300 (Minolta, Osaka, Japão) de acordo com o sistema CIE (L*, a* e b*), utilizando fonte de iluminação D65, com um ângulo de observação de $10^{\circ}$ e placa de calibração número 15233011 . Foram reali- 
zadas três medidas para cada amostra, diretamente sobre a amostra, sem vidro entre esta e o equipamento. Segundo CIE (1976) as coordenadas de cromaticidade $\mathrm{a}^{*} \mathrm{e} \mathrm{b}$, indicam a direção da cor, onde + a $^{*}$ é a direção para o vermelho e - $a^{*}$ é a direção para o verde, + b* é a direção para amarelo e - b* para o azul, sendo o L*a luminosidade.

\subsection{4 - Modificação química da fração rica em amido}

A fração de farinha de aveia rica em amido, com granulometria $<150 \mu \mathrm{m}$ foi fosfatada para obter baixo grau de substituição usando tripolifosfato de sódio $(0,126 \mathrm{~g} / \mathrm{g}$ de amido), segundo o método descrito por PASCHALL [25], com modificações. O processo de filtração foi substituído por centrifugação em $3.500 \mathrm{rpm}$ devido ao pequeno tamanho dos grânulos do amido de aveia (3 a $10 \mu \mathrm{m}$ ) que causavam problemas de entupimento do filtro. Além do tempo recomendado pela metodologia, de 20 min de aquecimento a seco a $150-155^{\circ} \mathrm{C}$, foi realizado um segundo tratamento de fosfatação em que o tempo de aquecimento foi de $40 \mathrm{~min}$.

Após a modificação química, a amostra suspensa em água a $5 \%(\mathrm{p} / \mathrm{v})$ foi dialisada contra água destilada, durante 7 dias a $4{ }^{\circ} \mathrm{C}$, com troca diária da água [31] para remoção completa do fósforo não ligado. A fração modificada foi então seca em estufa de ar forçado a $45^{\circ} \mathrm{C}$. O conteúdo de fósforo ligado ao amido foi determinado por colorimetria (espectrofotômetro de feixe simples, Femto, modelo 600) conforme metodologia descrita por SMITH \& CARUSO [34].

\subsection{5 - Avaliação das propriedades da fração modificada}

A fração modificada foi avaliada quanto à capacidade de ligação com água fria (CLAF) segundo MEDCALF \& GILLES [22], calculada segundo a Equação 1.

$$
\operatorname{CLAF}(\%)=\frac{\text { Peso da água ligada } \times 100}{\text { Peso do amido em base seca }}
$$

A claridade do gel armazenado sob refrigeração foi determinada segundo MORIKAWA \& NISHINARI [24], pela medida da porcentagem de transmitância (T\%) de uma solução de amostra a 1\% (p/v em água destilada) em espectrofotômetro a $650 \mathrm{~nm}$ (espectrofotômetro de feixe simples, Femto, modelo 600). Antes da leitura, o pH da solução foi ajustado para $6,5 \mathrm{com} \mathrm{NaOH}$, a amostra foi aquecida a $95{ }^{\circ} \mathrm{C}$ por 30 min e resfriada à temperatura ambiente. A cor foi medida no dia de preparo do gel (0) e após 14 dias de armazenamento a $5{ }^{\circ} \mathrm{C}$.

A sinérese dos géis a $5 \%(\mathrm{p} / \mathrm{v})$, preparados por aquecimento a $95{ }^{\circ} \mathrm{C}$ por $30 \mathrm{~min}$, foi determinada pela quantidade de água liberada, após 14 e 21 dias de armazenamento sob refrigeração $\left(5^{\circ} \mathrm{C}\right)$ e após um ciclo de congelamento a - $18{ }^{\circ} \mathrm{C}$ (por $24 \mathrm{~h}$ ) e descongelamento a $30{ }^{\circ} \mathrm{C}$, de acordo com BILIADERIS [3]. Durante essa avaliação, os géis foram mantidos em recipientes plásticos hermeticamente fechados para evitar a evaporação da água liberada. A perda de água foi determinada por pesagem e expressa em porcentagem em relação ao peso inicial.

\subsection{6 - Delineamento experimental e análise estatística}

O delineamento experimental utilizado foi inteiramente casualizado com três repetições por tratamento. Os resultados foram submetidos à análise de variância de uma via, seguida do teste de Duncan, em nível de 5\% de significância, exceto para os resultados da cor da pasta no dia 0 e após 14 dias, que foram submetidos à análise de variância, tratando-se o fator tempo como medida repetida. As análises foram realizadas utilizando o programa Statistica ${ }^{\circledR}$, versão 6.0.

\section{3 - RESULTADOS E DISCUSSÃO}

Durante o processo de fracionamento foi observado maior rendimento para as frações de maior e menor granulometria ( $>300 \mu \mathrm{m}$ e $<150 \mu \mathrm{m}$ ) (Tabela 1). KNUCKLES, CHIU \& BETSCHART [19] utilizando peneiras de 45, 75 e $147 \mu \mathrm{m}$, encontraram rendimento médio de 5,2\% para a fração mais grossa da farinha de aveia $(>147 \mu \mathrm{m})$, que foi a mais rica em $\beta$-glucanas (28\%). SÁ [27], ao avaliar o fracionamento seco da farinha de aveia da cultivar IAC 7 , encontrou rendimento das frações ricas em fibras, proteínas e das duas últimas de amido, de aproximadamente 7 , 12,48 e 30\%, utilizando peneiras de 180,150 e $106 \mu \mathrm{m}$, respectivamente. Esta discordância com os dois artigos, principalmente em relação à fração de maior granulometria, provavelmente está associada ao grau de moagem inicial da farinha, assim como ao tamanho das malhas das peneiras utilizadas. Segundo KNUCKLES, CHIU \& BETSCHART [19] os elevados teores de ß-glucanas nas frações de maior granulometria, ocorrem devido à associação das ß-glucanas com estruturas do cereal que apresentam maior resistência para redução de tamanho, destacando a importância da granulometria inicial para a concentração desse nutriente. Além destes fatores, o processo de desengorduramento e pré-secagem da farinha de aveia são procedimentos prévios indispensáveis para um bom rendimento do fracionamento, pois na presença de gordura e umidade pode haver formação de grânulos que bloqueiam as malhas das peneiras [2, 18, 19, 27]. GUTKOSKI \& EL-DASH [13] relatam que quanto menor a umidade maior o rendimento das frações inferiores $(<150 \mu \mathrm{m})$ para cariopses de aveia moída.

TABELA 1 - Rendimento do processo de fracionamento a seco da farinha de aveia ( $g \%)$.

\begin{tabular}{cc}
\hline Fração & Rendimento $(\mathbf{g} \%)$ \\
\hline$>300 \mu \mathrm{m}$ & $31,96 \pm 1,60^{\mathrm{a}}$ \\
$212-300 \mu \mathrm{m}$ & $13,67 \pm 2,56^{\mathrm{b}}$ \\
$150-212 \mu \mathrm{m}$ & $12,03 \pm 2,02^{\mathrm{b}, \mathrm{c}}$ \\
$<150 \mu \mathrm{m}$ & $35,51 \pm 3,48^{\mathrm{a}}$ \\
Perdas & $5,90 \pm 0,93^{\mathrm{c}}$ \\
\hline
\end{tabular}

Os valores (média \pm erro padrão da média; $n=4$ ) que não apresentam uma letra em comum diferem significativamente pelo teste de Duncan $(p<0,05)$. 
Os resultados obtidos para a composição da mistura de grãos das cultivares UFRGS 14 e 19 (Tabelas 2 e 3), encontram-se dentro dos padrões relatados por diversos autores e da média nacional [11, 23, 26, 41]. No entanto, a composição química média de grãos de aveia descascados com gordura, conforme os dados obtidos por PEDÓ \& SGARBIERI [26], é de 15,01\% para proteína; 1,12\% para açúcares; 53,26\% para amido; 11,12\% para fibra alimentar total; e 7,12\% para gordura.

As maiores concentrações de proteína foram observadas nas frações $>300 \mu \mathrm{m}$ e na intermediária 212-300 $\mu \mathrm{m}$ (Tabela 2). Os teores de fibra insolúvel, solúvel e total apresentaram comportamento semelhante, concentrando-se na fração > $300 \mu \mathrm{m}$ e na intermediária 212-300 $\mu \mathrm{m}$, diferindo estatisticamente dos níveis encontrados nas frações de 150-212 $\mu \mathrm{m}$ e $<150 \mu \mathrm{m}$ (Tabela 2).

Os maiores teores de cinzas foram observados na fração $>300 \mu \mathrm{m}$ e na intermediária 212-300 $\mu \mathrm{m}$ (Tabela 3), nas quais também foi observada maior concentração de fibras (farelo). Sabe-se que os minerais em geral se depositam em maior quantidade nas camadas externas do grão, onde se encontram geralmente associados às fibras [41], o que explica a relação observada no presente trabalho. O amido digerível e o resistente foram encontrados em teores mais expressivos na fração intermediária 150-2 $12 \mu \mathrm{m}$ e na $<150 \mu \mathrm{m}$ se comparadas às demais (Tabela 3 ).

Como citado anteriormente, para o adequado processo de concentração de nutrientes, com bom rendimento, faz- se necessário o desengorduramento da farinha a fim de se evitar a formação de barreiras físicas de grânulos entre as peneiras [2, 19, 27]. Após este processo, verificou-se redução significativa na porcentagem de extrato etéreo, de $5,06 \%$ na farinha integral com gordura, para 2,95\% na farinha integral desengordurada (Tabela 3). No entanto, estudos revelam que se pode reduzir até $65 \%$ dos lipídios da farinha de aveia [27, 39]. Apesar disso, não foi encontrada diferença significativa no teor de extrato etéreo entre a farinha integral desengordurada e as diferentes frações (Tabela 3), sugerindo que a redução de gordura obtida foi suficiente para permitir um bom fracionamento.

De acordo com o índice de concentração dos componentes estudados verificou-se que o método e a granulometria das peneiras (300, 212 e $150 \mu \mathrm{m}$ ) utilizadas proporcionaram uma excelente distribuição e concentração dos nutrientes (Tabela 4), permitindo obter frações com elevado índice de concentração em fibras e proteínas ( $>300 \mu \mathrm{m}$ e $212-300 \mu \mathrm{m}$ ), bem como outras enriquecidas em amido (150-212 $\mu \mathrm{m}$ e $<150 \mu \mathrm{m}$ ). SÁ [27] encontrou um índice de concentração de nutrientes homogêneo com poucas diferenças entre as frações de aveia obtidas. Este fato pode estar relacionado à abertura das peneiras utilizadas naquele estudo, que utilizou peneiras com granulometrias inferiores a $180 \mu \mathrm{m}$.

De acordo com o índice de concentração de nutrientes, verificou-se que as duas primeiras frações (enriquecidas em fibras e proteína) obtiveram concentração de nutrientes semelhante entre si, o mesmo ocorrendo para as duas

TABELA 2 - Teores de proteína bruta e fibra alimentar das frações de aveia em g\% de massa seca.

\begin{tabular}{|c|c|c|c|c|}
\hline Fração & Proteína bruta & Fibra insolúvel & Fibra solúvel & Fibra total \\
\hline Farinha integral desengordurada & $17,82 \pm 0,04^{c}$ & $5,02 \pm 0,01^{b}$ & $4,67 \pm 0,01^{c}$ & $9,69 \pm 0,01^{c}$ \\
\hline$>300 \mu \mathrm{m}$ & $27,92 \pm 0,27^{a}$ & $13,38 \pm 0,36^{a}$ & $15,12 \pm 0,36^{a}$ & $28,51 \pm 0,31^{a}$ \\
\hline $212-300 \mu \mathrm{m}$ & $26,57 \pm 0,02^{\mathrm{b}}$ & $14,01 \pm 1,22^{a}$ & $10,53 \pm 1,57^{b}$ & $24,55 \pm 0,35^{\mathrm{b}}$ \\
\hline $150-212 \mu m$ & $14,13 \pm 0,20^{\mathrm{e}}$ & $2,37 \pm 0,73^{c}$ & $1,83 \pm 0,06^{d}$ & $4,20 \pm 0,74^{d}$ \\
\hline$<150 \mu \mathrm{m}$ & $15,43 \pm 0,14^{d}$ & $1,89 \pm 0,31^{c}$ & $2,05 \pm 0,52^{d}$ & $3,94 \pm 0,63^{d}$ \\
\hline
\end{tabular}

Os valores (média \pm erro padrão da média; $\mathrm{n}=3$ ) da mesma coluna que não apresentam a mesma letra diferem significativamente pelo teste de Duncan ( $\mathrm{p}<0,05$ ).

TABELA 3 - Teores de cinzas, amido e extrato etéreo das frações de aveia em g\% de massa seca.

\begin{tabular}{|c|c|c|c|c|}
\hline Fração & Cinzas & Amido digerível & Amido resistente & Extrato etéreo \\
\hline Farinha integral desengordurada* & $2,31 \pm 0,14^{c}$ & $61,14 \pm 1,69^{b}$ & $3,39 \pm 0,09^{a, b}$ & $2,95 \pm 0,12^{\mathrm{a}}$ \\
\hline$>300 \mu \mathrm{m}$ & $5,18 \pm 0,19^{a}$ & $32,91 \pm 0,45^{d}$ & $2,96 \pm 0,25^{b}$ & $3,31 \pm 0,37^{a}$ \\
\hline $212-300 \mu \mathrm{m}$ & $4,18 \pm 0,16^{b}$ & $39,82 \pm 0,77^{c}$ & $2,98 \pm 0,11^{\mathrm{b}}$ & $3,17 \pm 0,02^{\mathrm{a}}$ \\
\hline $150-212 \mu \mathrm{m}$ & $1,30 \pm 0,13^{d}$ & $69,90 \pm 1,16^{a}$ & $3,78 \pm 0,29^{a}$ & $2,76 \pm 0,21^{a}$ \\
\hline$<150 \mu \mathrm{m}$ & $0,29 \pm 0,13^{e}$ & $68,95 \pm 2,95^{\mathrm{a}}$ & $3,61 \pm 0,10^{a}$ & $2,52 \pm 0,07^{a}$ \\
\hline
\end{tabular}

Os valores (média \pm erro padrão da média; $\mathrm{n}=3$ ) da mesma coluna que não apresentam a mesma letra diferem significativamente pelo teste de Duncan ( $<<0,05$ ).

TABELA 4 - Índice de concentração* dos componentes em cada fração de farinha de aveia comparada com a fração de farinha de aveia integral desengordurada.

\begin{tabular}{lcccccc}
\hline \multicolumn{1}{c}{ Fração } & Cinza & Proteína & $\begin{array}{c}\text { Amido } \\
\text { digerivel }\end{array}$ & $\begin{array}{c}\text { Amido } \\
\text { resistente }\end{array}$ & Fibra insolúvel & Fibra solúvel \\
\hline$>300 \mu \mathrm{m}$ & 2,24 & 1,56 & 0,53 & 0,87 & 2,66 & 2,23 \\
$212-300 \mu \mathrm{m}$ & 1,80 & 1,49 & 0,63 & 0,87 & 2,79 & 0,47 \\
$150-212 \mu \mathrm{m}$ & 0,56 & 0,79 & 1,14 & 1,25 & 0,39 \\
$<150 \mu \mathrm{m}$ & 0,12 & 0,86 & 1,12 & 1,06 & 0,37 \\
\hline
\end{tabular}


últimas frações (enriquecidas em amido) (Tabela 4). Por conseqüência, é possível a utilização apenas da peneira de $212 \mu \mathrm{m}$ para fracionar a farinha de aveia em frações ricas em fibras e amido.

Uma das características perceptíveis nas diferentes frações é a mudança de coloração. Analisando os dados da Tabela 5, observa-se que quanto menor a granulometria da fração maior é a sua luminosidade, o que provavelmente está relacionado com a maior quantidade de amido existente na fração intermediária 150-212 $\mu \mathrm{m}$ e na $<150 \mu \mathrm{m}$. Já a fração $>300 \mu \mathrm{m}$ apresentou luminosidade mais baixa, com valores de $a^{*} \mathrm{e} \mathrm{b}^{*}$ maiores que as demais, o que indica tendência ao vermelho e ao amarelo, respectivamente. Isto se deve à maior concentração de fibras, bem como à granulometria mais grosseira. Resultados semelhantes para os valores de coloração $L^{*}$, a* e b* foram relatados por GUTKOSKI \& EL-DASH [13] em estudo sobre a influência da umidade de armazenamento e temperatura de secagem na coloração de frações de farinha de aveia ( $>532 \mu \mathrm{m}, 532-150 \mu \mathrm{m}$ e $<150 \mu \mathrm{m})$. A exemplo do observado no presente trabalho, estes autores também destacam a influência da granulometria nas diferenças de coloração. A farinha integral desengordurada apresentou menor valor de b* (direção para o amarelo) quando comparada à farinha integral com gordura.

De modo geral, a cor da matéria-prima apresenta papel importante para definir a sua aplicação, pois farinhas ou frações mais escuras poderiam influenciar a coloração do alimento ao qual fossem incorporadas. Assim, a coloração das distintas frações de farinha de aveia obtidas deve ser levada em conta quando se propõe sua utilização.

TABELA 5 - Parâmetros de cor em farinha de aveia integral e suas frações obtidas por fracionamento a seco.

\begin{tabular}{lccc}
\hline \multicolumn{1}{c}{ Fração } & $\mathbf{L}^{*}$ & $\mathbf{a}^{*}$ & $\mathbf{b}^{*}$ \\
\hline Farinha integral & $96,62 \pm 0,46^{\mathrm{b}}$ & $0,20 \pm 0,02^{\mathrm{b}}$ & $2,10 \pm 0,11^{\mathrm{b}}$ \\
$\begin{array}{l}\text { Farinha integral } \\
\text { desengordurada }\end{array}$ & $96,94 \pm 0,13^{\mathrm{b}}$ & $0,17 \pm 0,01^{\mathrm{b}}$ & $-0,44 \pm 0,06^{\mathrm{d}}$ \\
$>300 \mu \mathrm{m}$ & $92,74 \pm 0,61^{\mathrm{c}}$ & $0,74 \pm 0,02^{\mathrm{a}}$ & $3,93 \pm 0,29^{\mathrm{a}}$ \\
$212-300 \mu \mathrm{m}$ & $95,70 \pm 0,42^{\mathrm{b}}$ & $0,26 \pm 0,03^{\mathrm{b}}$ & $0,41 \pm 0,10^{\mathrm{c}}$ \\
$150-212 \mu \mathrm{m}$ & $99,73 \pm 0,59^{\mathrm{a}}$ & $-0,45 \pm 0,02^{\mathrm{c}}$ & $-1,96 \pm 0,17^{\mathrm{e}}$ \\
$<150 \mu \mathrm{m}$ & $100,80 \pm 0,30^{\mathrm{a}}$ & $-0,63 \pm 0,03^{\mathrm{c}}$ & $-2,31 \pm 0,25^{\mathrm{e}}$ \\
\hline \multicolumn{2}{l}{ Os valores (média \pm erro padrão da média; $\mathrm{n}=3$ ) da mesma coluna que não apresentam } \\
\multicolumn{2}{l}{ a mesma letra diferem significativamente pelo teste de Duncan (p < 0,05 ). }
\end{tabular}

Apesar da coloração mais escura das frações ricas em fibras, estas têm grande potencial de aplicabilidade na indústria de alimentos, como fonte de fibras, especialmente de $\beta$-glucanas, que possuem comprovada propriedade funcional [5, 27, 40]. No entanto, as frações ricas em amido apresentam valor comercial bastante inferior, o que pode inviabilizar economicamente o processo de fracionamento. Neste sentido, a fosfatação do amido pode modificar suas propriedades reológicas, ampliando as suas possibilidades de aplicação na indústria de alimentos e, por conseguinte o seu valor comercial [28].

Dentro deste contexto, escolheu-se a fração enriquecida em amido, a qual apresentou maior rendimento no fraciona- mento $(<150 \mu \mathrm{m})$, a fim de modificar suas características funcionais pela fosfatação. Essa fração apresentava, antes da modificação, 0,21\% de fósforo (Tabela 6). Esse valor é inferior ao citado na literatura (300 a $400 \mathrm{mg} / 100 \mathrm{~g} \mathrm{de}$ fósforo) [9,41], o que pode ter ocorrido pelo processo de desengorduramento prévio da farinha de aveia, no qual podem ter sido removidos fosfolipídios ricos em fósforo [20]. A fosfatação da fração de farinha de aveia rica em amido $(<150 \mu \mathrm{m})$ aumentou os teores de fósforo em relação à fração de amido nativo (Tabela 6). A diálise foi utilizada para avaliar a quantidade de fósforo efetivamente ligado ao amido, pois remove o fósforo livre que permanece após a modificação. A variação do tempo de aquecimento usado no processo de modificação, de 20 para 40 min, não alterou a quantidade de fósforo ligado (Tabela 6).

Segundo a Portaria n ${ }^{\circ} 540$, de 27 de outubro de 1997 (Ministério da Saúde, Secretaria de Vigilância Sanitária, Brasil), os teores de fósforo residual em amidos monoéster fosfato (ex: esterificação com tripolifosfato de sódio) devem seguir a recomendação do Codex Alimentarius [16], que preconiza teor de fósforo residual de no máximo $0,4 \%$, exceto para amidos de batata ou trigo que podem ter teores de até $0,5 \%$. Deste modo, ambos os amidos fosfatados obtidos (20 e $40 \mathrm{~min}$ ) encontram-se adequados para uso em alimentos.

TABELA 6 - Teores de fósforo ( $\mathrm{g} \%)$ nas frações ricas em amido $(<150 \mu \mathrm{m})$ nativa e modificada.

\begin{tabular}{lcc}
\hline Fonte de amido & Fósforo total $(\mathbf{g} \%)$ & Fósforo após diálise \\
\hline Amido nativo & $0,21 \pm 0,01^{\mathrm{c}}$ & N.D. \\
Fosfatado $20 \mathrm{~min}$ & $0,51 \pm 0,01^{\mathrm{a}}$ & $0,39 \pm 0,01^{\mathrm{a}}$ \\
Fosfatado $40 \mathrm{~min}$ & $0,37 \pm 0,03^{\mathrm{b}}$ & $0,32 \pm 0,02^{\mathrm{a}}$
\end{tabular}

Os valores (média \pm erro padrão da média; $n=3$ ) da mesma coluna que não apresentam a mesma letra diferem significativamente pelo teste de Duncan $(\mathrm{p}<0,05)$. N.D. = não determinado.

Vários estudos relatam mudanças benéficas nas propriedades do amido de diversas fontes a partir da modificação química por fosfatação, destacando-se a redução do grau de sinérese, aumento da capacidade de ligação à água fria e da claridade das pastas armazenadas sob refrigeração [28, 29, $32,33,36]$. No entanto, não foram encontrados trabalhos avaliando a fosfatação do amido de aveia.

A capacidade de ligação de água fria (CLAF) aumentou após a fosfatação, sendo superior para a fração fosfatada por $20 \mathrm{~min}$, seguida pela fração fosfatada por $40 \mathrm{~min}$ e pela nativa (Tabela 7). Esses resultados encontram-se diretamente associados aos teores de fósforo presentes nas amostras (Tabela 6), sendo atribuídos à capacidade das moléculas de fosfato de absorver maiores quantidades de água nos produtos onde são aplicadas.

STAHL [36] verificou que a modificação química com baixo grau de substituição por 20 min não alterou a CLAF dos amidos de milho e pinhão. Essa discordância nos resultados está relacionada aos teores de fósforo, uma vez que os amidos fosfatados avaliados por este autor apresentavam 
TABELA 7 - Capacidade de ligação de água fria (CLAF) e sinérese após 1 ciclo de congelamento/descongelamento da fração $<150 \mu \mathrm{m}$ nativa e fosfatada por aquecimento por $20 \mathrm{ou}$ 40 min.

\begin{tabular}{lrc}
\hline Fonte de Amido & CLAF (g\%) & $\begin{array}{c}\text { Sinérese após congelamento/ } \\
\text { descongelamento } \\
\text { (\% de água liberada) }\end{array}$ \\
\hline Amido nativo & $76,29 \pm 4,41^{\mathrm{c}}$ & $56,99 \pm 0,90^{\mathrm{a}}$ \\
Fosfatado 20 min & $255,45 \pm 5,03^{\mathrm{a}}$ & $11,46 \pm 1,99^{\mathrm{b}}$ \\
Fosfatado 40 min & $146,04 \pm 4,01^{\mathrm{b}}$ & $8,85 \pm 1,75^{\mathrm{b}}$ \\
\hline
\end{tabular}

Os valores (média \pm erro padrão da média, $\mathrm{n}=3$ ) da mesma coluna que não apresentam a mesma letra diferem significativamente pelo teste de Duncan $(p<0,05)$.

teores de fósforo $(0,25$ e $0,28 \%$ para os amidos de milho e pinhão, respectivamente) semelhantes aos da fração de amido de aveia nativa do presente estudo (Tabela 6 ).

Pela fosfatação, a fração rica em amido de aveia reduziu a sinérese após descongelamento (Tabela 7), o que indica boa estabilidade a ciclos de congelamento/descongelamento. Não foi observada diferença nos valores de água liberada entre os amidos modificados por 20 ou 40 min. Resultados semelhantes para a estabilidade de amidos fosfatados foram relatados por SCHIRMER, TOLEDO \& REYS [29], estudando amido de milho, e por STAHL [36] avaliando diferentes graus de fosfatação em amido de pinhão e milho. Outros constituintes (proteínas, fibras e lipídios) possivelmente tenham contribuído para a retrogradação da fração de amido de aveia nativo, resultando em sinérese elevada, o que também foi observado por HOOVER \& SENANAYAKE [15] para sinérese total de 5 ciclos de congelamento/descongelamento de amidos nativos de Avena sativa, L. e Avena nuda, L. (65,3 e $62,2 \%$, respectivamente). A estabilidade aos ciclos de congelamento/descongelamento conferida pela fosfatação possibilita o uso da fração rica em amido em produtos congelados, assim como já relatado para amidos de outras fontes [4, 17, 20].

No presente trabalho, foi verificado que as duas frações fosfatadas apresentaram menor grau de sinérese (\% liberação de água) sob refrigeração quando comparadas à fração nativa. A fração fosfatada durante 40 min apresentou a menor porcentagem de água liberada, tanto após 14 quanto 21 dias de armazenamento a $5{ }^{\circ} \mathrm{C}$ (Figura 1 ). Essas características comprovam a eficiente mudança nas propriedades reológicas do amido fosfatado, relevante para a sua utilização industrial. Para CRUZ \& EL DASH [8], a incorporação de fosfato no amido previne a retrogradação e conseqüente sinérese, pois evita um contato maior entre as moléculas de amilose que se solubilizam durante o aquecimento e saem do interior do grânulo, impedindo a formação de microcristais, responsáveis pela retrogradação.

A avaliação da porcentagem de transmitância dos géis armazenados durante 14 dias sob refrigeração $\left(5^{\circ} \mathrm{C}\right)$ revelou redução significativa na claridade das pastas de todas as amostras, destacando-se a de amido nativo com redução de aproximadamente 24 vezes na sua claridade (Figura 2). A tendência à redução da claridade da pasta de amidos armazenada sob refrigeração está relacionada principal-

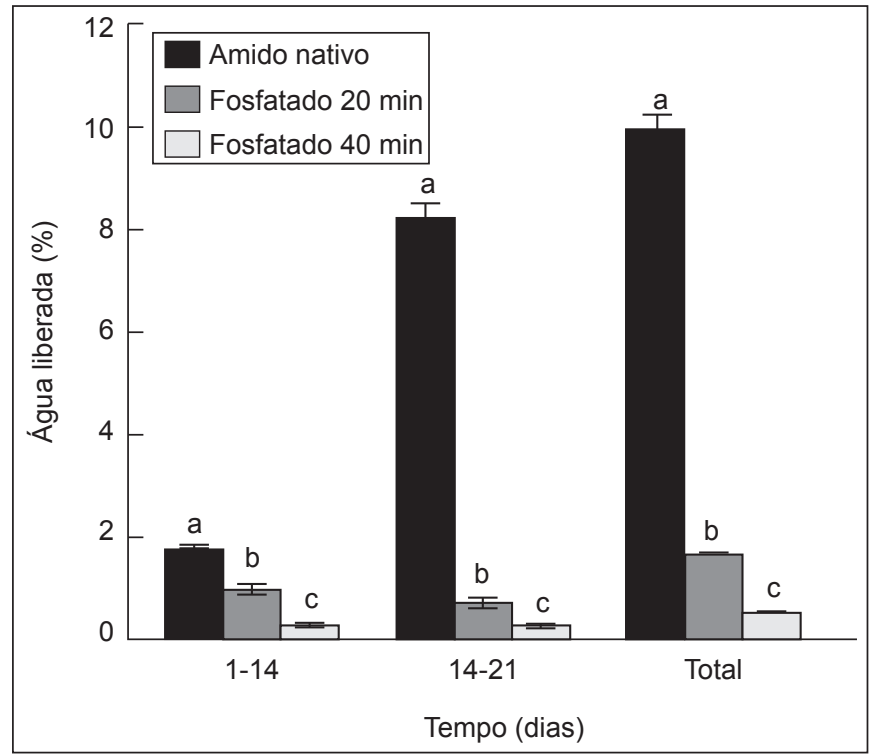

FIGURA 1 - Sinérese da fração $<150 \mu \mathrm{m}$ nativa e fosfatada, obtida por aquecimento por 20 ou 40 min. Os valores são média \pm erro padrão da média $(\mathrm{n}=3)$. As barras do mesmo tempo de armazenagem que não apresentam letras em comum diferem significativamente pelo teste de Duncan $(\mathrm{p}<0,05)$.

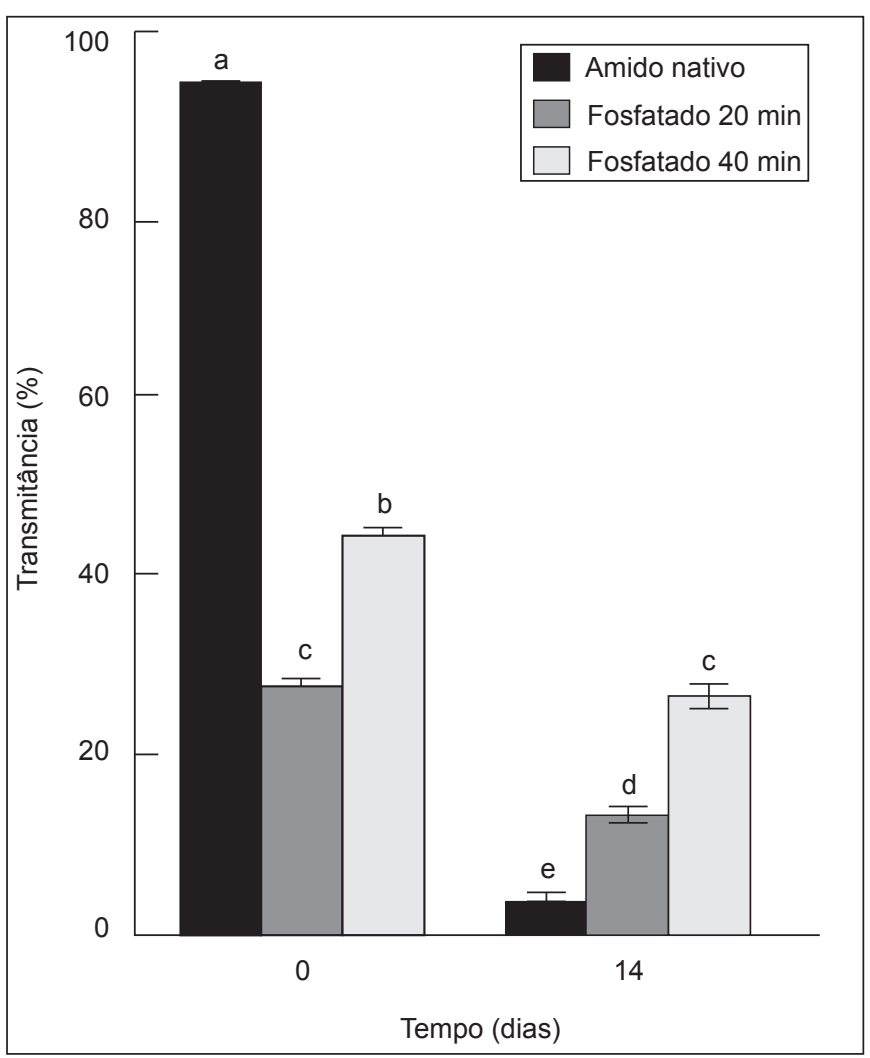

FIGURA 2 - Transparência dos géis da fração $<150 \mu \mathrm{m}$ nativa e fosfatada obtida por aquecimento por 20 ou 40 min durante armazenamento refrigerado. Os valores (média \pm erro padrão da média, $\mathrm{n}=3$ ) que não apresentam a mesma letra diferem significativamente pelo teste de Duncan $(\mathrm{p}<0,05)$. 
mente à sua retrogradação. Geralmente amidos com maior resistência à retrogradação não reduzem a claridade de suas pastas [36]. Além disso, estudos realizados por WANG \& WHITE [38] revelam que a presença de lipídios diminui a claridades das pastas, ou seja, quanto maior a porcentagem de lipídios maior a coloração opaca das pastas de amido de aveia. HOOVER \& SENANAYAKE [15] relatam ainda, que o pH da solução influencia a claridade de pastas de amidos nativos de Avena sativa L e Avena nuda L, pois quanto mais básico maior a transmitância das pastas de amido. De acordo com os resultados observados (Figura 2) embora os amidos fosfatados por 20 e 40 min tenham apresentado claridade inicial da pasta pouco acentuada, ao longo da armazenagem tiveram redução de aproximadamente 2 e 1,67 vezes o valor inicial, respectivamente. Esses valores indicam uma tendência pouco acentuada à retrogradação, corroborando os resultados obtidos nos testes de sinérese.

\section{4 - CONCLUSÕES}

Um fracionamento rápido, eficiente e a seco da farinha de aveia visando à concentração de nutrientes se mostrou possível utilizando-se apenas a peneira de $212 \mu \mathrm{m}$. A maior concentração de fibras/proteína ficou na fração $>212 \mu \mathrm{m} \mathrm{e}$ de amido na fração $212 \mu \mathrm{m}$. A modificação química da fração rica em amido (< $150 \mu \mathrm{m}$ ) por fosfatação (20 e 40 min) melhorou as propriedades das pastas, aumentando a CLAF e reduzindo a sinérese. Desta forma, torna-se possível propor o fracionamento a seco da farinha de aveia, com a finalidade de obter matérias-primas diferenciadas nutricionalmente para a alimentação humana. O processo de fosfatação das frações ricas em amido melhora suas propriedades de pasta e ampliam seu espectro de uso na indústria de alimentos, aumentando o valor comercial.

\section{5 - REFERÊNCIAS BIBLIOGRÁFICAS}

[1] AOAC. Official methods of analysis of the Association of the Official Analysis Chemists, 16. ed. Arlington: Association of Official Analytical Chemists, 1995.

[2] BHATTY, R. S. Extraction and enrichment of beta-Dglucan from barley and oat brans. Cereal Chem., v. 70, n. 1, p. 73-77,1993.

[3] BILIADERIS, C. G. Physical characteristics, enzymatic digestibility and structure of chemically modified smooth pea and waxy maize starches. J. Agr. Food Chem., v. 30, p. 925-931, 1982.

[4] CEREDA, M. P.; WOSIACK, G. Characterization of pinhão starch. Part II. Rheological properties of the pastes. Starch/Stärke, v. 37, p. 404-407, 1985.

[5] COFRADES, S.; HUGHES, E.; TROY, D. J. Effects of oat fibre and carrageenan on the texture of frankfurters formulated with low and high fat. Eur. Food Res. Technol., v. 211, p. 19-26, 2000.

[6] COLLEONI-SIRGHIE, M.; JANNINK, J. L.; KOVVALENKO, I.; BRIGGS, J.; WHITE, P. J. Prediction of ßglucan concentration based on viscosity evaluations of raw oat flours from high ß-glucan and traditional oat lines. Cereal Chem., v. 81, n. 4, p. 434-443, 2004.
[7] COLlEONI-SIRGHIE, M.; JANNINK, J. L.; WHITE, P. J. Pasting and thermal properties of flours from oat lines with high and typical amounts of $ß$-glucan. Cereal Chem., v. 81, n. 6, p. 686-692, 2004.

[8] CRUZ, R.; EL DASH, A. A. M. Amido de chuchu (Seichium edule, Swartz). Efeito de fosfatação em sua viscosidade. Bol. SBCTA, v. 18, n. 4, p. 371-378, 1984.

[9] DENARDIN, C. C.; SILVA, L. P.; VAZ, M. A. Composição mineral de cultivares de aveia na região sul do Brasil, 2004. In: REUNIÃO DA COMISSÃO BRASILEIRA DE PESQUISA DE AVEIA, XXIV, 2004, Pelotas. Resultados Experimentais... Pelotas: Comissão Brasileira de Pesquisa de Aveia, 2004, p. 590.

[10] ELIASSON, A.C.; GUDMUNDSSON, M. Starch: physicochemical and functional aspects. In: ELIASSON, A. C. (Ed.) Carbohydrates in food. New York: Marcel Dekker, 1996. p. 431-503.

[11] GATTO, L.; FLOSS, E. L.; CASTOLDI, F. L. Características químicas de grãos de aveia branca, 2005. In: Reunião da Comissão Brasileira de Pesquisa de Aveia, XXV, 2005, Ponta Grossa. Resultados Experimentais... Ponta Grossa: Comissão Brasileira de Pesquisa de Aveia, 2005, p. 259-262.

[12] GUDMUNDSSON, M.; EliASSON, A. C. Some physicochemical properties of oats starches extracted from varieties with different oil content. Acta Agr. Scand., v. 39, n. 1, p. 101-111, 1989.

[13] GUTKOSKI, L. C.; EL-DASH, A. A. Avaliação de características físico-químicas de frações de moagem de aveia. Braz. J. Food Technol., v. 2, n. 1-2, p. 149-154, 1999.

[14] HOOVER, R.; VASANTHAN, T. Studies on isolation and characterization of starch from oat (Avena nuda) grains. Carbohyd. Polym., v. 19, n. 4, p. 285-297, 1992.

[15] HOOVER, R.; SENANAYAKE, S. P. J. N. Composition and physicochemical properties of oat starches. Food Res. Int., v. 29, n. 1, p. 15-26, 1996.

[16] JECFA. Modified starches. Monograph 1. In: Codex General Standard for Food Additives (GFSA) Online Database. Disponível em: <http://www.codexalimentarius.net/gsfaonline/additives/search.html>. Acesso em: 15 abril 2006.

[17] KIM, C. T.; SHIH, F. F; CHAMPAGNE, E. T.; DAIGLE, K. Effects of phosphorylating salts and temperature on the preparation of rice starch phosphates by extrusion. Starch/Stärke, v. 51, n. 8-9, p. 280-286, 1999.

[18] KNUCKLES, B. E.; CHIU, M. M. $\beta$-glucan enrichment of barley fractions by air classification and sieving. $\mathbf{J}$. Food Sci., v. 60, n. 5, p. 1070-1074, 1995.

[19] KNUCKLES, B. E.; CHIU, M. M.; BETSCHART, A. A. $\beta$-glucan enriched fractions from laboratory-scale dry milling and sieving of barley and oats. Cereal Chem., v. 69, n. 2, p. 198-202, 1992.

[20] LIM, S.; SEIB, P. A. Preparation and pasting properties of wheat and corn starch phosphates. Cereal Chem., v. 70, n. 2, p. 137-144, 1993.

[21] MÃLKKI, Y.; MYLLYMÃKI, K.; AUTIO, K.; SUORTTI, T. Preparation and properties of oat bran concentrates. Cereal Food. World, v. 37, n. 9, p. 693-700, 1992. 
[22] MEDCALF, D. G.; GILlES, K. A. Wheat starches. I. Comparison of physicochemical properties. Cereal Chem., v. 42, p. 558-568, 1965.

[23] MONTEIRO, F. Diferentes proporções de fibra insolúvel e solúvel de grãos de aveia sobre a resposta biológica de ratos. 2005, 42 f. Dissertação (Mestrado em Ciência e Tecnologia dos Alimentos), Universidade Federal de Santa Maria (UFSM), Santa Maria, 2005

[24] MORIKAWA, K.; NISHINARI, K. Effects of concentration dependence of retrogradation behavior of dispersions for native and chemically modified potato starch. Food Hydrocolloid, v. 14, p. 395-401, 2000.

[25] PASCHALL, E. F. Phosphation with inorganic phosphate salts. In: WHISTLER, R. L. (Ed) Methods in Carbohydrate Chemistry. New York: Academic Press, 1964. v. IV, p. 294-296.

[26] PEDÓ, I.; SGARBIERI, V. C. Caracterização química de cultivares de aveia (Avena sativa L). Ciênc. Tecnol. Aliment., v. 17, n. 2, p. 78-83, 1997.

[27] SÁ, R. M. Fracionamento de farinha de aveia (Avena sativa L.) para concentração de nutrientes. Florianópolis, 1998, 89 f. Dissertação (Mestrado em Ciência de Alimentos) Universidade Federal de Santa Catarina (UFSC). Florianópolis, 1998.

[28] SCHIRMER, M. A.; TOLEDO, M. C. F. REYES, F. G. R. Amido fosfatado de milho. Parte I. Efeito da temperatura e do tempo de tratamento térmico. Bol. SBCTA, v. 20, n. 1/2, p. 55-66, 1986

[29] SCHIRMER, M. A.; TOLEDO, M. C. F. REYES, F. G. R. Amido fosfatado de milho. Parte II. Obtenção e propriedades. Bol. SBCTA, v. 20, p. 153-179, 1986.

[30] SCHRICKEL, D. J.; CLARK, W. L. Estado actual de los programas para el mejoramento de la calidad proteínica de la avena. In: SCHRICKEL, D. J.; CLARK, W. L. (Ed.) Mays de alta calidad proteíca. México: Ed Limusa, 1977. p. 433-446.

[31] SITOHY, M. Z.; LABIB, S. M.; RAMADAN, M. F. Optimizing the conditions for starch dry phosphorylation with sodium mono-and dihidrogen orthophosphate under heat and vacuum. Starch/Stärke, v. 52, n. 4, p. 95-100, 2000.

[32] SITOHY, M. Z.; EL-SAADANY, S. S.; LABIB, S. M.; RAMADAN, M. F. Physicochemical properties of different types of starch phosphate monoesters. Starch/Stärke, v. 52, n. 4, p. 101-105, 2000.

[33] SIVAK, M. N.; PREISS, J. Industrial applications of starch. In: SIVAK, M. N.; PREISS, J. Starch: basic science to biotechnology. Advances in food nutrition research, v. 41, p. 163-170, 1998.
[34] SMITH, R. J.; CARUSO, J. L. Determination of phosphorus In: WHISTLER, R. L. (Ed) Methods in carbohydrate chemistry. New York: Academic Press, 1964. p. 42-46.

[35] SOWA, S. M. H.; WHITE, P. J. Characterization of starch isolated from oat groats with different amounts of lipid. Cereal Chem., v. 69, n. 5, p. 521-527, 1992.

[36] STAHL, J. A. Efeito da modificação por fosfatação sobre as características do amido de pinhão (Araucaria angustifolia, Bert, O. Ktze). 2003, 128 f. Dissertação (Mestrado em Ciência e Tecnologia dos Alimentos), Universidade Federal de Santa Maria (UFSM). Santa Maria, 2003.

[37] WALTER, M. Amido resistente: metodologias de quantificação e resposta biológica em ratos. 2005, 96 f. Dissertação (Mestrado em Ciência e Tecnologia dos Alimentos), Universidade Federal de Santa Maria (UFSM). Santa Maria, 2005.

[38] WANG, L. Z.; WHITE, P. J. Structure and physicochemical properties of starches from oats with different lipid contents. Cereal Chem., v. 71, n. 5, p. 443-450, 1994.

[39] WOOD, O. P. J.; WEISZ, J.; FEDEC, P. Potencial for $\beta$ glucan enrichment in brans derived from oat (Avena sativa L.) cultivars of different $\beta$-D-glucan concentrations. Cereal Chem., v. 68, n. 1, p. 48-51, 1991.

[40] YILMAZ, I.; DAGHOGLU, O. The effect of replacing fat with oat bran on fatty acid composition and physicochemical properties of meatballs. Meat Sci., v. 65, n. 2, p. 819-823, 2003.

[41] YOUNGS, V. L.; FORSBERG, R. A. Oat. In: OLSON, R. A.; FREY, K. J. (Ed.) Nutritional quality of cereal grains: genetic and agronomic improvement. Madison: Amer Society of Agronomy, 1987. Cap. 10, p. 457-497.

[42] ZHOU, M.; ROBARDS, K. K.; GLENNIE-HOLMES, M.; HELLIWELL, S. Structure and pasting properties of oat starch. Cereal Chem., v. 75, n. 3, p. 273-281, 1998.

\section{6 - AGRADECIMENTOS}

Os autores agradecem à CAPES pelo apoio financeiro (PROAP); à Estação Experimental da Universidade Federal do Rio Grande do Sul (Eldorado do Sul - RS) pelo fornecimento das amostras de aveia; à Novozymes Latino America Ltda. pela doação das enzimas; e à Doles (GO, Brazil) pela doação do kit GOP. A. P. Daniel foi bolsista de Mestrado/UFSM CAPES. C. Steffens foi bolsista PIBIC-CNPq/UFSM. T. Emanuelli é bolsista de produtividade em pesquisa do CNPq (proc. 304257/2004-4). L. P. Silva é bolsista PRODOC-CAPES. 